\title{
Modeling Grid-Connected Hybrid Electric Vehicles Using ADVISOR
}

\author{
Tony Markel ${ }^{\mathrm{a}}$ and Keith Wipke ${ }^{\mathrm{a}}$ \\ ${ }^{a}$ National Renewable Energy Laboratory, 1617 Cole Blvd., Golden, CO 80401
}

\begin{abstract}
The overall system efficiency of a hybrid electric vehicle is highly dependent on the energy management strategy employed. In this paper, an electric utility grid-connected energy management strategy for a parallel hybrid electric vehicle is presented. ADVISOR was used as a modeling tool to determine the appropriate size of the hybrid components and the energy management strategy parameter settings. Simulation results demonstrated that with this strategy it is possible to achieve double the fuel economy of a comparable conventional vehicle while satisfying all performance constraints. In addition, the final vehicle design provides an all-electric range capability in excess of 20 miles.
\end{abstract}

\section{Introduction}

Hybrid electric vehicles are under development today by various manufacturers. These vehicles are currently marketed as one way to improve the efficiency of our transportation system and to help reduce our dependence on and consumption of foreign petroleum. Engineers at the National Renewable Energy Laboratory (NREL) with the support of the US Department of Energy (DOE) have developed a software tool to help engineers in the automotive industry make educated design decisions during the early stages of development of new hybrid electric vehicles. Typically, there are multiple designs that may meet or exceed the perceived demands of the customer. This software package, called ADVISOR, allows users to quickly move through the initial stages of vehicle design.

ADVISOR has been built in the Matlab/Simulink computing environment and is freely available via the Internet (http://www.nrel.gov/transporation/analysis). The program evaluates the performance of a vehicle in a combined backward-forward facing approach (1). On a time basis, the program calculates what is required from each component, working backwards through the vehicle from the wheels to the powerplant, in order for the vehicle to follow the desired speed trace. As the requirements are passed from one component to the next, performance limits are enforced. On the forward path, the performance of the downstream components is updated based on limits enforced in upstream components. This approach simplifies the calculation process and eliminates the need to iteratively solve at each time step. The disadvantage in this approach is that it is difficult to generate true control algorithms that can be carried directly to a finished product.

Existing hybrid electric designs can be broken into three basic categories, 1) series, 2) parallel, and 3) combined series/parallel (2). The vehicle is characterized by the connection of the various components within the vehicle and the energy flow pathway. A series hybrid consists of a powerplant providing electricity (i.e. internal combustion engine (ICE)/generator combination, or fuel cell system) to a battery pack. The vehicle is then propelled by an electric drive motor. The powerplant is not coupled directly to the wheels and can run in its most efficient operating region. In a parallel hybrid, the powerplant (ICE) and the electric motor can both provide power to the driveline in parallel. This design provides a direct mechanical path for power delivery between the engine and the wheels. A combined series/parallel hybrid, like the Toyota Prius, exhibits some of the characteristics of both parallel and series hybrids.

The vehicle configurations can then be grouped into subcategories by the vehicle energy management strategy. A common energy management strategy employed today is a charge-sustaining strategy. In this case, the state of charge (SOC) of the battery pack will be maintained by the onboard powerplant as necessary. An alternative approach is a charge-depleting or grid-connected strategy $(3,4)$. This strategy relies mainly on grid electricity to charge the battery pack while the vehicle is not in use. It attempts to fully utilize the capabilities of both the battery pack and the on-board powerplant. While in use, the vehicle will use the battery pack and electric motor alone to propel the vehicle when it is most efficient to do so. The on-board powerplant is used as the primary power source only when it would not be an effective use of battery power (i.e. high-speed operation) or to maintain the state of charge of the battery pack. The advantages of this strategy include its ability to use off-peak electricity and to provide emissions free operation for extended periods. It is possible that a large portion of normal driving could be covered all electrically with this approach. A major drawback of this strategy is the cost and weight penalties incurred due to a large electric drive system.

NREL recently participated in the Hybrid Electric Vehicle Working Group (HEV/WG) by providing modeling support in the analysis of the potential of hybrid electric vehicles, including grid-connected hybrids. The HEV/WG focused on 3 vehicle classes; small car, mid-size car, and sport utility vehicle and 4 vehicle designs; conventional (CV) and parallel hybrids with minimal (HEV0), 20 miles (HEV20), 60 miles (HEV60) of all-electric range capability (5). The

Copyright ${ }^{\odot} 2001$ IEEE. Reprinted from "Sixteenth Annual Battery Conference on Applications and Advances: Proceedings of the Conference 9-12 January 2001, Long Beach, California." This material is posted here with permission of the IEEE. Such permission of the IEEE does not in any way imply IEEE endorsement of any of NREL's products or services. Internal or personal use of this material is permitted. However, permission to reprint/republish this material for advertising or promotional purposes or for creating new collective works for resale or redistribution must be obtained from the IEEE by writing to pubs-permissions@ieee.org. By choosing to view this document, you agree to all provisions of the copyright laws protecting it. 
HEV/WG was lead by the Electric Power Research Institute (EPRI) with representation from government, the auto industry, the utility industry, and academia.

As a result of NREL's participation in the HEV/WG several model enhancements were made to ADVISOR to provide the capability to model grid-connected hybrid electric vehicles. This paper will provide an overview of a gridconnected energy management strategy as modeled using ADVISOR 3.0. It will also highlight the flexibility of such a vehicle. It should be noted that the results published here are based on knowledge obtained through participation in the HEV/WG. However, the results presented in this paper constitute an entirely separate study with a smaller scope.

\section{Energy Management Strategy}

The energy management strategy of a hybrid electric vehicle is extremely important. It defines how and when energy and power will be provided or consumed by the various components within the vehicle. In a grid-connected hybrid electric vehicle the strategy will attempt to bias the energy flows towards battery pack usage while the pack exhibits a high state of charge. As the state of charge of the pack begins to fall, the strategy will bias the energy usage more towards the engine in order to maintain state of charge in the pack and to prevent pack damage and reduced cycle life. This strategy has characteristics of both a charge-
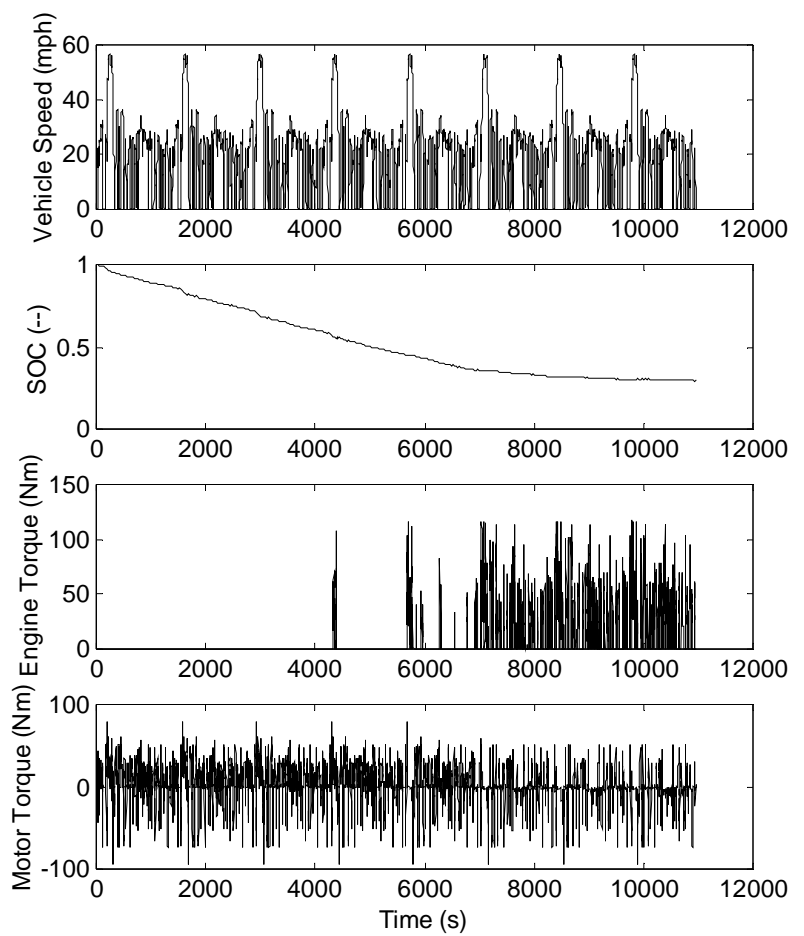

Figure 1: Vehicle Operation Using Grid-Connected Energy Management Strategy on Repeated UDDS depleting and a charge-sustaining strategy. Figure 1 shows graphically how this biasing is applied based on battery pack state of charge while simulating vehicle operation over eight Urban Dynamometer Drive Schedules (UDDS). As the SOC falls, usage of the engine increases while usage of the electric motor decreases, thus reducing the rate of decrease of the SOC.

Table 1: Energy Management Strategy Parameters

\begin{tabular}{|l|c|l|}
\hline Name & Units & Description \\
\hline cs_lo_soc & -- & $\begin{array}{l}\text { lowest desired SOC of } \\
\text { battery pack }\end{array}$ \\
\hline cs_hi_soc & -- & $\begin{array}{l}\text { highest desired SOC of } \\
\text { battery pack }\end{array}$ \\
\hline cs_charge_trq & Nm & $\begin{array}{l}\text { load applied to the engine } \\
\text { to charge/discharge the } \\
\text { batteries based on SOC }\end{array}$ \\
\hline cs_min_trq_frac & -- & $\begin{array}{l}\text { fraction of maximum } \\
\text { engine torque above which } \\
\text { engine must operate if } \\
\text { SOC<cs_lo_soc }\end{array}$ \\
\hline cs_electric_launch_spd_lo & m/s & $\begin{array}{l}\text { vehicle speed below which } \\
\text { vehicle attempts to run all } \\
\text { electrically at low SOC }\end{array}$ \\
\hline cs_electric_launch_spd_hi & m/s & $\begin{array}{l}\text { vehicle speed below which } \\
\text { vehicle attempts to run all } \\
\text { electrically at high SOC }\end{array}$ \\
\hline
\end{tabular}

This biasing within the strategy is achieved through an engine on/off state computer and logic to determine the amount of power to request from the engine when it is on. The main parameters used to implement this control logic in ADVISOR for charge-depleting hybrid electric vehicles have been detailed in Table 1.

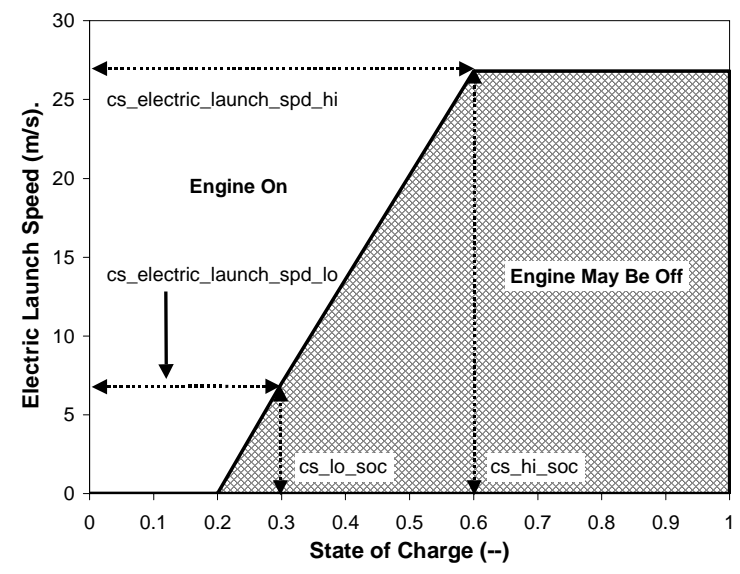

Figure 2: Vehicle Electric Launch Speed Energy Management Strategy

Figure 2 provides a graphical representation of the electric launch speed control strategy parameter application. Based on the current SOC and vehicle speed the engine state can be determined. Above the solid line the engine will be on while below the solid line the vehicle will attempt to run all electrically. 
The following basic engine state computer has been implemented in the charge-depleting strategy in ADVISOR:

Engine must be on if,

1) motor/battery power is insufficient to meet the driver demand

Engine can be off if,

1) vehicle speed is less than electric launch speed

2) driveline torque demand is negative (i.e. deceleration event)

Figure 3 depicts the engine load modification strategy graphically. When the engine is on, the torque requested of the engine by the driveline may be modified based on the battery pack SOC to provide more or less power which enforces battery charging or discharging, respectively. The strategy employed is a simple linear model which requests cs_charge_trq when SOC=cs_lo_soc, -cs_charge_trq when SOC $=$ Cs_hi_soc, and interpolates at SOC's within this range. This load is in addition to the driveline load. Finally, a minimum engine torque fraction may be enforced if the SOC falls below the cs_lo_soc setting.

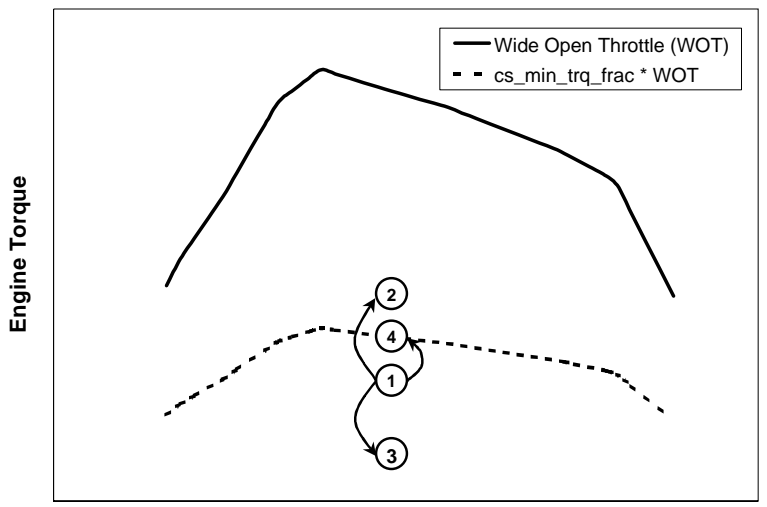

Engine Speed

Figure 3: Engine Load Modification Strategy, 1) Drivetrain Load, 2) Modified Load @ SOC=cs_lo_soc, 3) Modified Load@ @OC=cs_hi_soc, 4) Modified Load @ SOC $<$ cs_lo_soc

\section{Vehicle Assumptions and Constraints}

In this study the performance constraints and the vehicle assumptions will be the same as those used in the study by the $\mathrm{HEV} / \mathrm{WG}$ for the mid-size vehicle which were based on the conventional vehicle. Table 2 details the basic vehicle assumptions while Table 3 defines the performance constraints used in this study.
Table 2: Vehicle Assumptions

\begin{tabular}{|l|c|c|}
\hline Name & Value & Units \\
\hline Aerodynamic drag coefficient & 0.327 & -- \\
\hline Coefficient of rolling resistance & 0.008 & -- \\
\hline Frontal area & 2.174 & $\mathrm{~m}^{2}$ \\
\hline Wheel radius & 0.313 & $\mathrm{~m}$ \\
\hline Vehicle glider mass $^{1}$ & 1053 & $\mathrm{~kg}$ \\
\hline Average electrical accessory load & 500 & $\mathrm{~W}$ \\
\hline Average DC/DC converter efficiency & 85 & $\%$ \\
\hline Average air conditioning load (SC03 only) & 2000 & $\mathrm{~W}$ \\
\hline
\end{tabular}

Table 3: Performance Constraints

\begin{tabular}{|c|c|c|}
\hline Attribute & Value & Special Conditions \\
\hline \multicolumn{3}{|l|}{ Gradeability } \\
\hline $\begin{array}{l}\text { @ } 50 \text { mph for } \\
15 \text { min. }\end{array}$ & $7.2 \%$ & $\begin{array}{l}\text { 1) initial SOC = charge sustaining SOC } \\
\text { 2) final SOC }>20 \%\end{array}$ \\
\hline $\begin{array}{l}\text { @ } 30 \mathrm{mph} \text { for } \\
30 \mathrm{~min} \text {. }\end{array}$ & $7.2 \%$ & $\begin{array}{l}\text { 1) initial SOC = charge sustaining SOC } \\
\text { 2) final SOC }>20 \%\end{array}$ \\
\hline \multicolumn{3}{|l|}{ Acceleration } \\
\hline 0-60 mph & $9.5 \mathrm{~s}$ & 1) initial SOC = charge sustaining SOC \\
\hline 50-70 mph & $5.1 \mathrm{~s}$ & \\
\hline ZEV Range & 40 miles & composite of city and highway operation \\
\hline Top Speed & $>90 \mathrm{mph}$ & \\
\hline Trace miss & $<2 \mathrm{mph}$ & UDDS, HWFET, US06, and SC03 ${ }^{2}$ \\
\hline $\begin{array}{l}\text { Cycle charge- } \\
\text { sustaining SOC }\end{array}$ & $>20 \%$ & UDDS, HWFET, US06, and SC03 \\
\hline
\end{tabular}

In Table 3, the terms initial SOC, final SOC, and chargesustaining SOC have been introduced. The initial SOC is the state of the battery pack at the start of the test and the final SOC is the state at the end of the test. The chargesustaining SOC is the SOC at which the vehicle when driven over a typical drive cycle will start and end at the same state. In this analysis the charge-sustaining SOC was between 0.2 and 0.3 depending on the drive cycle.

\section{Design Process}

The following steps define the design process employed:

1) Select baseline components

2) Resize components as necessary based on performance constraints

3) Optimize control strategy parameters for fuel economy and electric range on drive cycles.

Table 4: Hybrid Vehicle Base Components

\begin{tabular}{|l|c|l|}
\hline Component & ADVISOR Filename & Description \\
\hline Engine & FC_CI67_emis & Volkswagen 1.9 L TDI (67 kW) \\
\hline $\begin{array}{l}\text { Traction } \\
\text { Motor }\end{array}$ & MC_PM49 & $\begin{array}{l}\text { Honda EV Plus 49 kW } \\
\text { Permanent Magnet Motor }\end{array}$ \\
\hline Transmission & TX_5SPD_CI & $\begin{array}{l}\text { 5-speed manual geared for CI } \\
\text { engines }\end{array}$ \\
\hline Battery Pack & ESS_45NIMH_Ovonic & Ovonic 45 Ah NiMH Module \\
\hline
\end{tabular}

\footnotetext{
${ }^{1}$ Vehicle glider mass is equal to vehicle curb weight minus powertrain mass.

${ }^{2}$ UDDS = Urban Dynamometer Driving Schedule; HWFET = Highway Fuel Economy Test; US06 = high speed aggressive driving cycle, SC03 = extreme thermal load driving schedule. These cycles are used or will be used in federal procedures in the near future to quantify the fuel economy and emissions performance of vehicles.
} 
In this study the components detailed in Table 4 were selected from the ADVISOR database as the baseline components. The $1.9 \mathrm{~L}$ Volkswagen engine was selected because it is a fairly modern diesel engine with a highresolution data set collected by Oak Ridge National Laboratory. The Honda EV Plus motor was selected because it carries with it a high degree of confidence. Honda engineers using ADVISOR contributed this data set. It is appropriate technology (permanent magnet) for this application since the vehicle will operate as an electric vehicle during a large portion of typical driving. Finally, the Ovonic 45 Ah NiMH modules were selected based on their performance specifications of $67 \mathrm{Wh} / \mathrm{kg}$ and $550 \mathrm{~W} / \mathrm{kg}$ as quoted by Ovonic (3). The high specific energy of these modules should lead to significant all-electric range for a small weight penalty.

These base components may not be just the right size to provide the desired vehicle performance but they exhibit the state of the art performance characteristics desired in this study. Using ADVISOR the base components will be linearly scaled as necessary to satisfy the design objectives.

To determine the appropriate component sizes for this vehicle many performance aspects must be evaluated simultaneously. These include,

- Acceleration

- Gradeability

- Drive cycle operation from a high SOC (EV mode)

- Drive cycle operation from a low SOC (hybrid mode)

- $\quad$ Electric range

\section{Electric Range and Battery Pack Size}

In this study all electric range (AER) is assumed to end when the engine first turns on during a drive cycle. ${ }^{3}$ In addition, a second parameter, defined as EV miles, will be calculated. This second parameter is the sum of all miles driven with the engine off. All of these miles can not be counted as emissions free miles because at some point after the end of the AER, the engine is on. Once the engine has been used to propel the vehicle, it has provided kinetic energy to the vehicle. Some of this energy will at some point during the cycle be collected via regenerative braking and stored in the battery for future use. In addition, some of the battery energy may have come directly from the engine via the charge maintenance algorithm. As a result, this energy stored in the battery can be associated at least in part to engine operation and emissions production. Thus the propulsion energy can no longer be considered emissions free even though the vehicle is propelled electrically.

\footnotetext{
3 This assumption is based on current test procedures of Society of Automotive Engineers (SAE J1711, 1999) and the California Air Resources Board (CARB, 1999).
}

If an electric drivetrain efficiency of $250 \mathrm{Wh} / \mathrm{mi}$ is assumed then to achieve 40 miles of all electric operation, a pack with $10 \mathrm{kWh}$ of useful energy is required. Assuming that only $75 \%$ of the pack capacity is usable on a daily basis then a $13.3 \mathrm{kWh}$ pack results. Using the Ovonic $45 \mathrm{Ah}$ modules this results in a pack consisting of 22 modules connected in series. This pack, capable of $88 \mathrm{~kW}$ at $50 \%$ SOC, will increase the base vehicle mass by $185 \mathrm{~kg}$. This pack is considerably larger than those used in production hybrids today (Toyota Prius $\sim 1.8 \mathrm{kWh}$, Honda Insight $\sim 0.9$ $\mathrm{kWh}$ ). It is likely that this pack will cost 5-10 times that of packs in current hybrids simply based on rated capacity.

\section{Drive Cycle Operation and Motor Size}

In this study, the motor size was primarily defined by the drive cycle operation from a high SOC. Secondly, it should be matched to the battery pack capabilities. For the current Federal Test Procedure standards, the vehicle must not miss the speed trace by more than $2 \mathrm{mph}$ at any time. It was assumed that these standards would carry over to the additional drive cycles that compose the SAE J1711 Recommended Practice (6). For this vehicle to follow all of the acceleration events below the vehicle electric launch speed in the US06 cycle it required an electric motor of 73.5 $\mathrm{kW}$. To achieve this power level it was assumed that the electronic controls of the motor could be modified to allow short duration operation of $50 \%$ higher than its continuous operating region. As a result, it was not necessary to scale the base electric motor. This effectively allows the electric motor to operate at higher load fractions and thus higher efficiency a majority of the time.

\section{Drive Cycle Operation and Engine Size}

With the electric components sized, the minimum engine size to satisfy grade, acceleration, and drive cycle requirements was determined. A small engine is important to allow significant gains in operating efficiency while in charge-sustaining mode. In this analysis, operating in the charge-sustaining mode on the US06 cycle was the active constraint that determined the engine size. A $38 \mathrm{~kW}$ engine was required to maintain the state of charge of the battery pack. The mass and torque capability of the base engine was scaled linearly to satisfy this requirement. In combination with the electric components, this engine size produced a vehicle that exceeded the grade and acceleration performance constraints.

Table 5 summarizes the final component sizes based on enforcement of all of the active vehicle performance constraints. 
Table 5: Final Vehicle Component Characteristics

\begin{tabular}{|l|c|c|}
\hline \multicolumn{1}{|c|}{ Parameter } & Value & Units \\
\hline Engine Peak Power & 38 & $\mathrm{~kW}$ \\
\hline Motor Peak Power & 73.5 & $\mathrm{~kW}$ \\
\hline Battery Pack Capacity $^{4}$ & 13.5 & $\mathrm{kWh}$ \\
\hline Battery Pack Power $^{5}$ & 88 & $\mathrm{~kW}$ \\
\hline Vehicle Mass & 1545 & $\mathrm{~kg}$ \\
\hline Vehicle Test Mass & 1681 & $\mathrm{~kg}$ \\
\hline
\end{tabular}

\section{Parametric Study on Energy Management Strategy}

With the vehicle components defined, the next step was to evaluate the energy management strategy options. This was accomplished using ADVISOR's built-in parametric study capabilities.

First, desirable values of cs_charge_trq and cs_min_trq_frac were determined. Refer to Table 1 and Figure 3 for descriptions of these parameters. Both of these parameters

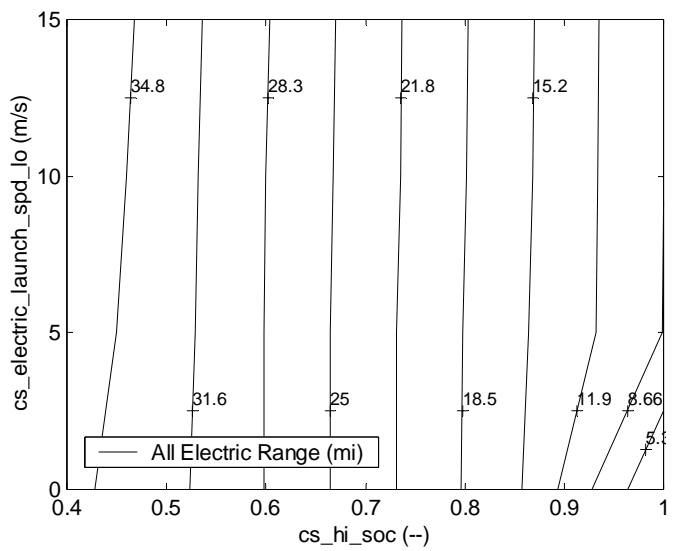

Figure 4: All Electric Range after Completion of 60 Miles of UDDS Operation

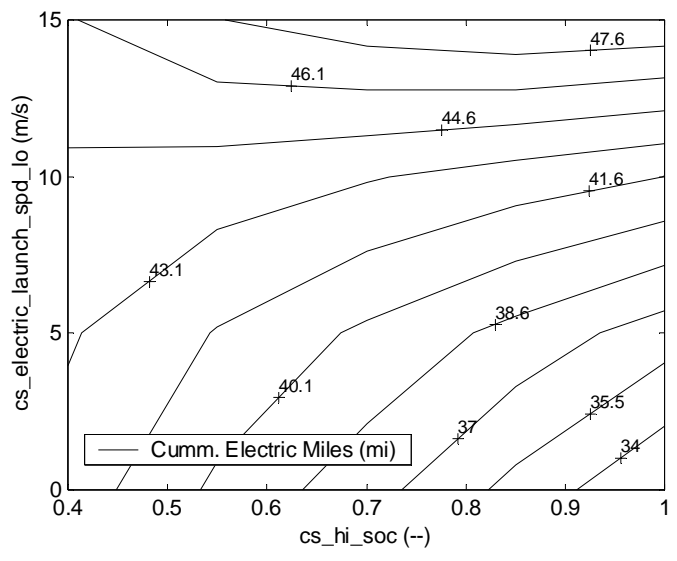

Figure 5: Cumulative EV Miles after Completion of 60 Miles of UDDS Operation

${ }^{4}$ Capacity from $100 \%$ to $0 \%$ SOC at C/1 constant current discharge.

${ }^{5}$ Maximum power at $50 \%$ SOC above minimum voltage (200 V) for 10 second duration. Assumed internal resistance of $0.2134 \mathrm{Ohms}$ at $50 \%$ SOC. attempt to modify the engine load to maintain the state of charge in the battery pack while preventing inefficient engine operation. The cs_charge_trq parameter is slightly more flexible because it provides the ability to discharge the pack as desired and it is functional at all states of charge rather than just below the low SOC setting. The cs_min_trq_frac parameter is useful for preventing very low engine load points. Therefore, cs_min_trq_frac was set to 0.1 (i.e. $10 \%$ engine load). To provide charge-sustaining operation on the US06 drive cycle, cs_charge_trq was set to $10 \mathrm{Nm}$. However, it was also determined that to provide acceptable charge-sustaining operation on the SC03 cycle, the cs_charge_trq parameter would need to be $25 \mathrm{Nm}$. It was assumed that the on-board vehicle computer would be intelligent enough to adjust this charge maintenance parameter based on knowledge that the air conditioning system is in use.

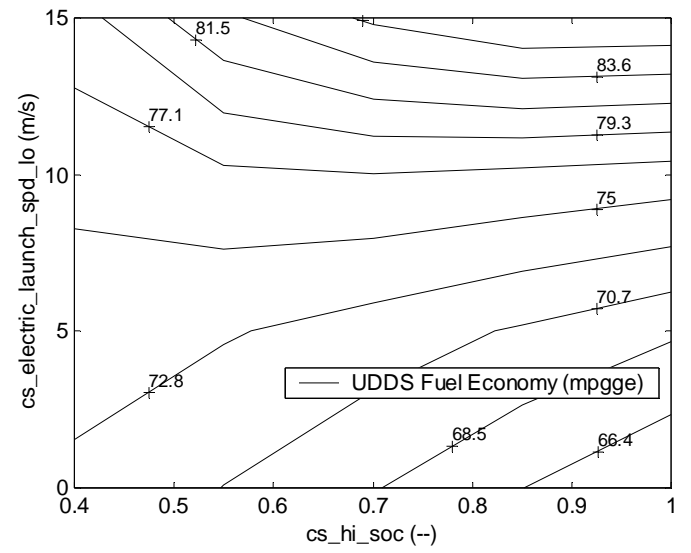

Figure 6: Fuel Economy (gasoline equivalent) after Completion of 60 miles of UDDS Operation

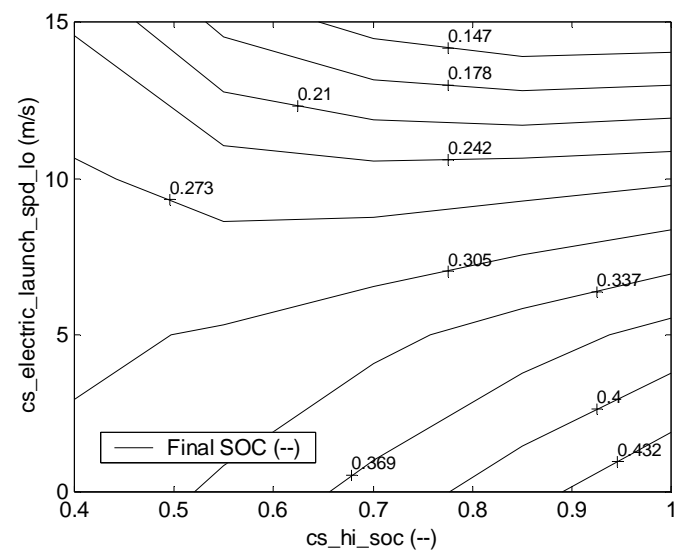

Figure 7: Final SOC after Completion of 60 miles of UDDS Operation

Next, it was necessary to define how the vehicle will operate with the battery pack between the high state of charge and low state of charge. Figure 2 shows the basic 
implementation of the vehicle speed and battery pack state dependent engine operation. Remember that above the solid line, the engine will be on, while below the line the vehicle will try operate all electrically. All four of the parameters defining this curve are adjustable. For this study, cs_lo_soc was fixed at 0.3 to force the charge sustaining operation to be between $20 \%$ and 30\% SOC for all drive cycles. Additionally, cs_electric_launch_spd_hi was fixed at 26.8 $\mathrm{m} / \mathrm{s}$ to provide significant AER on the UDDS and HWFET cycles. The effects of the other two parameters, cs_hi_soc and cs_electric_launch_spd_lo, on AER, EV miles, fuel economy, and final SOC were then evaluated through a parametric study.

Figure 4 through Figure 7 provide a summary of the parametric study results. For each parameter set, the vehicle was simulated over 8 repeated UDDS cycles with the first cycle starting with a full state of charge. For each case, ADVISOR stored the resulting AER, EV miles, fuel economy and final SOC.

Several conclusions can be drawn from these plots. Based on Figure 4, it is clear that the AER is only a function of cs_hi_soc. By comparing Figure 6 to Figure 5 and to Figure 4 , it is clear that the gasoline equivalent fuel economy is more a function of cumulative EV miles than it is of AER. The fuel economy contour trends are more similar to the EV miles contours than the AER contours. Lastly, it is important to note that as the cs_electric_launch_spd_lo increases, the final SOC decreases dramatically as shown in Figure 7. This means that the charge-sustaining point in these cases maybe significantly below the $20 \%$ constraint. Based on this study, the cs_hi_soc was set at 0.6 and the cs_electric_launch_spd_lo was set at $7 \mathrm{~m} / \mathrm{s}$. This provides a vehicle with sufficient AER to qualify for significant Partial Zero Emission Vehicle (PZEV) credits by CARB standards. It also achieves significant EV miles and provides excellent fuel economy while offering charge-sustaining operation near 0.3 SOC on the UDDS cycle. Note that a vehicle with less than 20 miles of AER can only qualify for up to 0.3 PZEV credits. Also note that the AER constraint of 40 miles has been relaxed in this design in favor of more EV miles and better fuel economy although the vehicle is still capable of satisfying the constraint with a different set of control strategy parameters. Clearly, this energy management

Table 6: Final Energy Management Strategy Parameter Settings

\begin{tabular}{|l|c|c|}
\hline Name & Value & Units \\
\hline CS_lo_soc & 0.3 & -- \\
\hline CS_hi_soc & 0.6 & -- \\
\hline CS_charge_trq & $10^{6}$ & Nm \\
\hline cs_min_trq_frac & 0.1 & -- \\
\hline cs_electric_launch_spd_lo & 7 & $\mathrm{~m} / \mathrm{s}$ \\
\hline cs_electric_launch_spd_hi & 26.8 & $\mathrm{~m} / \mathrm{s}$ \\
\hline
\end{tabular}

\footnotetext{
${ }^{6}$ cs_charge_trq $=25 \mathrm{Nm}$ for SC03 cycle only
}

approach provides considerable flexibility and the chosen design is only one possibility. Table 6 summarizes the final energy management strategy parameter settings for this study.

\section{Results}

\section{Acceleration and Gradeability}

To confirm that this design satisfies the initial constraints, the acceleration and gradeability performance of the vehicle was quantified using ADVISOR. Table 7 summarizes the vehicle performance. In Table 7 the grade performance for 15 minutes is measured using an initial SOC of $30 \%$ and a final SOC of $20 \%$ while the continuous performance is measured with the battery pack disabled.

Table 7: Acceleration and Gradeability Performance

\begin{tabular}{|c|c|c|}
\hline Characteristic & Value & Units \\
\hline Acceleration & & $\mathrm{s}$ \\
\hline 0-60 mph & 8.9 & $\mathrm{~s}$ \\
\hline 50-70 mph & 4.8 & $\mathrm{mph}$ \\
\hline Top speed & 98.7 & \\
\hline Gradeability & & $\%$ \\
\hline @ 50 mph for 15 min. & 7.9 & $\%$ \\
\hline @ 50 mph continuously & 7.5 & \\
\hline
\end{tabular}

\section{SAE J1711 Recommended Practice}

The J1711 Recommended Practice provides guidelines for the evaluation of emissions and fuel economy of hybrid electric vehicles. Figure 8 provides a diagram of the various parts of the test. The partial charge test (PCT) measures performance in charge-sustaining operation while the full charge test (FCT) measures all electric range and performance in electric mode. The PCT-CV and FCT-EV are required tests only for vehicles with an operator initiated conventional-only or electric-only modes, respectively.

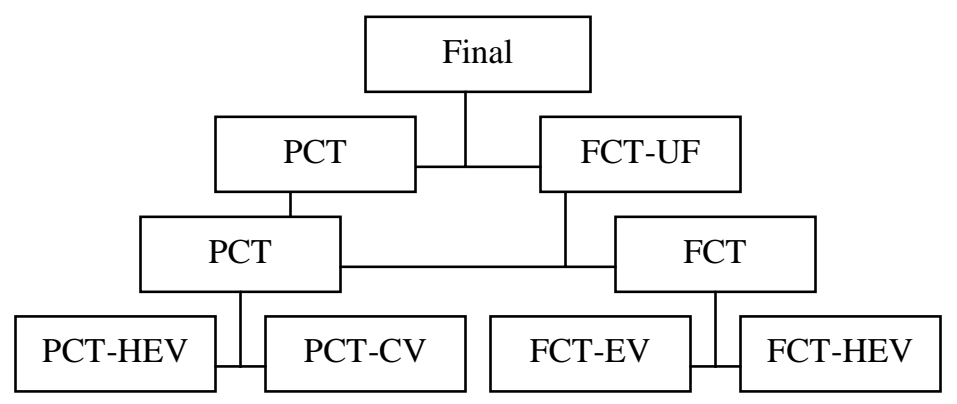

Figure 8: SAE J1711 Recommended Practice Test Matrix

The FCT tests are only run for vehicles with off-board charge capability. Based on the electric range measurement the vehicle is given a utility factor (UF). The utility factor is used to weight the FCT and PCT results to produce the FCT-UF value and to account for the limited utility (range) of the FCT mode. The final value is then the average of PCT and FCT-UF. The final value assumes that it is as likely that the vehicle will start each day with a partial 
charge as it is that it will leave with a full charge. By design, a grid-connected vehicle should be fully charged each evening. Therefore, the FCT-UF value is the most appropriate value to consider for these vehicles if operated as designed. Each of the tests shown in the tree is performed for four drive cycles; UDDS, HWFET, US06, and SC03.

This entire recommended practice has been coded into ADVISOR and when initiated, provides a special results screen with a tree format like the one shown in Figure 8. Table 8 provides a summary of the J1711 test results for this vehicle. The US06 and SC03 fuel economy data is presented only for reference purposes. These cycles will be used only for emissions certification.

Table 8: SAE J1711 Results Summary

\begin{tabular}{|l|c|c|c|c|c|}
\hline & Units & UDDS & HWFET & US06 & SC03 \\
\hline $\begin{array}{l}\text { Partial Charge } \\
\text { Test }\end{array}$ & & & & & \\
\hline Fuel Economy & mpgge & 43.0 & 50.0 & 34.9 & 32.4 \\
\hline Final SOC & -- & 0.279 & 0.335 & 0.211 & 0.21 \\
\hline Full Charge Test & & & & & \\
\hline AER & mi & 23.7 & 24.5 & 0.8 & 16.1 \\
\hline Utility Factor (UF) & -- & 0.356 & 0.366 & 0.016 & 0.263 \\
\hline Charge Energy & kWh & 8.86 & 7.77 & 8.26 & 10.96 \\
\hline Fuel Economy & mpgge & 104.8 & 91.6 & 45.1 & 58.8 \\
\hline Fuel Economy, UF & mpgge & 54.4 & 60.0 & 35.0 & 36.7 \\
\hline $\begin{array}{l}\text { Fuel Economy, } \\
\text { Final }\end{array}$ & mpgge & 48.1 & 54.5 & 34.9 & 34.4 \\
\hline
\end{tabular}

The results in Table 8 show that the fuel economy both on the partial charge test and the full charge test vary widely depending on the drive cycle. The SC03 cycle fuel economies are low due to the large electrical accessory load of the air conditioning system while the US06 economies are low because of its aggressive behavior. The full charge test results include both the energy required to charge the battery back to its initial state (with an assumed wall charger efficiency of 85\%) and any fuel used. In comparison, the conventional vehicle on which this vehicle is based achieves approximately $27 \mathrm{mpg}$ city/highway composite. Compared to the utility factor weighted fuel economy results (Table 9), it is clear that the grid-connected energy management strategy in a parallel hybrid vehicle could provide a doubling of the fuel economy with respect to a comparable conventional vehicle.

Table 9: Composite Fuel Economy Comparison

\begin{tabular}{|l|c|c|c|}
\hline & Units & Conventional & Hybrid \\
\hline Composite Fuel Economy & mpgge & 27 & 56.8 \\
\hline
\end{tabular}

\section{Conclusions}

In this paper a grid-connected energy management strategy for a parallel hybrid electric vehicle was discussed. ADVISOR was used to determine both the appropriate component sizes and the control strategy parameter values.
These results showed that it is possible to achieve a doubling of the fuel economy over a comparable conventional vehicle while still satisfying performance constraints. The final vehicle design provided greater than 20 mile all electric range capability. This characteristic would allow the vehicle to qualify for significant PZEV credits. However, since the grid-connected hybrid vehicle design requires a large energy storage system, it is likely that there will be a significant incremental cost associated with this design. It was also demonstrated that the vehicle could be designed to achieve significant electric miles beyond the AER. The additional electric miles contribute to a composite utility factor weighted fuel economy of 56.8 mpgge for city and highway driving.

\section{Acknowledgments}

The authors would like to acknowledge the entire HEV/WG for their dedication, patience, and assistance during the entire HEV/WG project. Special recognition is due to Mark Kosowski (General Motors) for his contributions of data and working knowledge; Andy Frank (Univ. of California, Davis) for his creative ideas and know-how; and Michael Lechner (Electric Power Research Institute) for his leadership.

\section{References}

1. Wipke, K., Cuddy, M., Burch, S., ADVISOR 2.1: A User-Friendly Advanced Powertrain Simulation Using a Combined Backward/Forward Approach. IEEE Transactions on Vehicular Technology: Special Issue on Hybrid and Electric Vehicles. 1999.

2. Cuddy, M., Wipke, K., Analysis of the Fuel Economy Benefit of Drivetrain Hybridization. SAE 970289, 1997.

3. Corrigan D., et al, Nickel-Metal Hydride Batteries for ZEV-Range Hybrid Electric Vehicles. $17^{\text {th }}$ Intl. Electric Vehicle Symposium. Montreal, Canada. 2000.

4. Alexander, M., et al, A Mid-Size Sedan Design for High Fuel Economy and Low Emissions: The UC Davis FutureCar. 1999.

5. HEV/WG Draft Final Report. 2000.

6. SAE J1711 Recommended Practice for Measuring the Exhaust Emissions and Fuel Economy of HybridElectric Vehicles. 1999. 